\section{Año LI. urtea}

$128-2019$

Uztaila-abendua Julio-diciembre

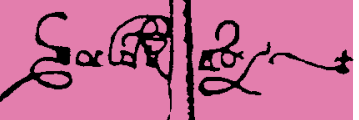
tats

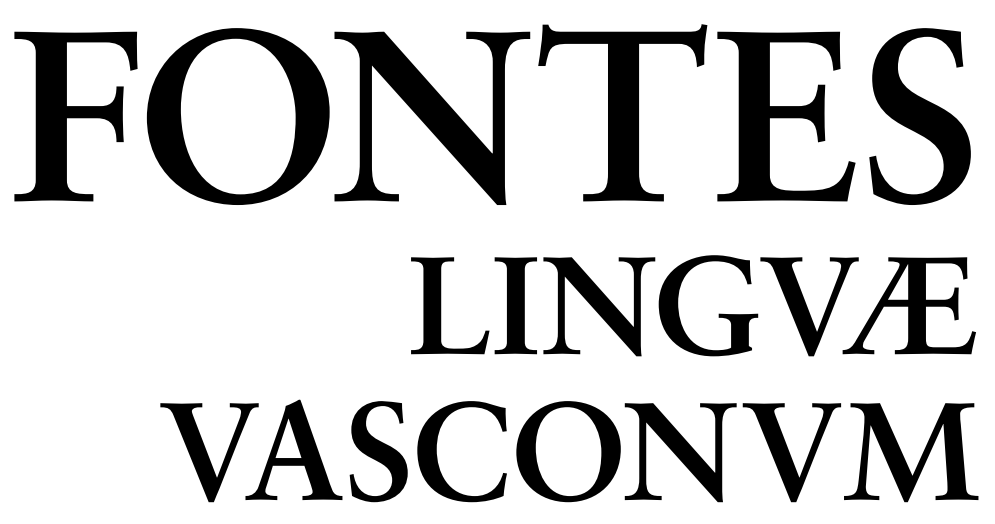

STVDIA ET DOCVMENTA

SEPARATA

\title{
Baztango 1750eko \\ eliza-agindua: \\ edizioa eta azterketa
}

Urtzi Reguero Ugarte

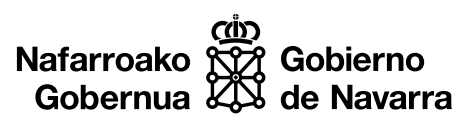

- 00 


\section{Baztango 1750eko eliza-agindua: edizioa eta azterketa}

Edicto eclesiástico de 1750 en la variante dialectal de Baztan: edición y estudio

Ecclesiastic edict of 1750 written in a dialectal variety of Baztan: edition and analysis

Urtzi Reguero UGARTE

Euskal Herriko Unibertsitatea (UPV/EHU)

urtzi.reguero@ehu.eus

Lan hau MINECOk finantzatutako Monumenta Linguae Vasconum (V): periodizazioa eta kronologia (FFI: 2016-76032-P) ikerketa proiektuaren eta Eusko Jaurlaritzak lagundutako Historia de la lengua vasca y lingüística histórico-comparada (IT1344-9) ikerketa taldearen baitan egin da.

Eskerrak eman nahi dizkiet Eneko Zuloagari eta Ekaitz Santaziliari lanaren aurreko bertsio bat irakurri eta egindako zuzenketa eta oharrengatik. Halaber, aldizkariko errebisatzaile anonimoak ere eskertu nahi ditut egindako ohar baliagarriengatik. Bistan denez, lanean dauden hutsak nireak besterik ez dira. 


\section{LABURPENA}

Saio honen helburua da 1750ean Gaspar Miranda eta Argaitz Iruñeko gotzainak dantzak debekatzeko aginduaren euskarazko itzulpenaren edizioa aurkeztea; horretarako Baztango Elbeten eta Elizondon jasotako bi aldaerak erabili dira. Testuak lehendik ere ezagunak baziren ere, saio honetan lehen aldiz eskaintzen dira Elbeteko eta Elizondoko aldaerak batera eta osorik, edizio kritiko batean. Edizioaren ondoren, testuaren azterketa dialektologikoa egiten da eta zenbait ohar ematen dira testuaren fidagarritasun dialektalaz.

Gako hitzak: testu zaharrak; eliza-agindua; Baztan; euskalkiak; dialektologia; filologia; fidagarritasuna.

\section{RESUMEN}

El objetivo principal de este trabajo es presentar la edición crítica del edicto eclesiástico en el que se prohibieron los bailes públicos. Fue ordenado en 1750 por el obispo de Pamplona Gaspar Miranda y Argaitz y el edicto fue traducido al euskera. Para la presente edición nos basamos en las variantes conocidas de Elbete y Elizondo, ambas localidades del valle del Baztán. Aunque los dos textos eran conocidos antes, en este trabajo se presentan por primera vez ambas versiones juntas y completas en una edición crítica. El trabajo concluye con un estudio dialectológico del euskera utilizado y se habla sobre su fiabilidad dialectal.

Palabras clave: textos antiguos; edicto eclesiástico; Baztan; dialectos vascos; dialectología; filología; fiabilidad.

\section{ABSTRACT}

The main aim of this paper is to present a critical edition of an ecclesiastic edict that forbade public dances. This edict was ordered by Gaspar Miranda y Argaitz, the bishop of Pamplona, in 1750 and was translated into Basque, in a dialectal variant of Elbete and Elizondo, both villages of Baztan. Even though the texts were well-known, in this paper both are presented in full length and together for the first time in a critical edition. In addition, a dialectological analysis is presented as well in order to illustrate the dialectal reliability.

Keywords: old texts; ecclesiastic edict; Baztan; Basque dialects; dialectology; philology; reliability. 
1. Sarrera. 2. Fontes criticae pixka bat. 3. Edizioaz bi ohar. 4. Testua. 5. HiZKUNTZA-IRUZKINA. 6. TESTUAREN FIDAGARRITASUN DiALEKTALAZ ZENBAit OHAR. 7. ERREFERENTZIAK.

\section{SARRERA}

1750eko martxoaren 12an Iruñeko Gaspar Miranda eta Argaitz gotzainak dantzak debekatzen zituen agindua plazaratu zuen: «Edicto en que se prohíben los bailes y danzas públicas y el uso de los instrumentos profanos en iglesias y funciones eclesiásticas, y se persuade a las personas eclesiásticas el mayor cuidado y vigilancia sobre la extirpación de estos desórdenes y abusos, que se manda sentar y publicar en los primeros días de Pascua de Resurrección a cada años» dio Elizondoko gaztelaniazko bertsioaren aurkezpenak. Halakoetan ohi bezala, jatorrizko idatzia gaztelaniaz dago eta parrokia guztietako kontu liburuetan kopiatu behar izan zuten; ustez bederen, aginduaren idazlea Sebastian Mendiburu izan zen (Bidador, 2004, 37. or.). Edonola ere zenbait parrokiatan euskaratu egin zuten Iruñeko gotzainaren agindua. Orotara, orduko euskarazko hiru testu iritsi dira gugana: bi Baztangoak dira, Elizondokoa bata eta Elbetekoa bestea; aldiz, hirugarrena Orriokoa da, Ezkabartekoa -ik. Satrustegi (1984, 1987, 80-81. or.)-.

Ikusiko dugunez, Baztango bi testuek etorki berbera dute; Orrioko itzulpena, ordea, bestelakoa da. Goi-nafarrerazko beste aldaera bat erabiltzeaz gain, laburragoa da eta Larramendiren eragina duela ematen du, Baztangoek ez bezala, aginduaren Orrioko itzulpenean bertan agertzen den gaistaquinteguia 'oficina de maldades' hitzak sala dezakeenez (Reguero, 2017, 778. or.). Baztangoek, horren ordainetan, «oficina» dakarte, gaztelaniazkoak bezala. Baztangoen eta Orriokoaren artean dauden diferentzia handi horiek direla eta, saio honetan lehen biak bakarrik jaso dira. 
Elbete eta Elizondoko bi lekukotasunak kontuan harturik, beraz, aise ikus daiteke oso antzekoak direla eta aldaera grafiko txiki batzuk besterik ez dituztela desberdin ${ }^{1}$. Beraz, bi testuen arteko harremanari begira hiru aukera ditugu:

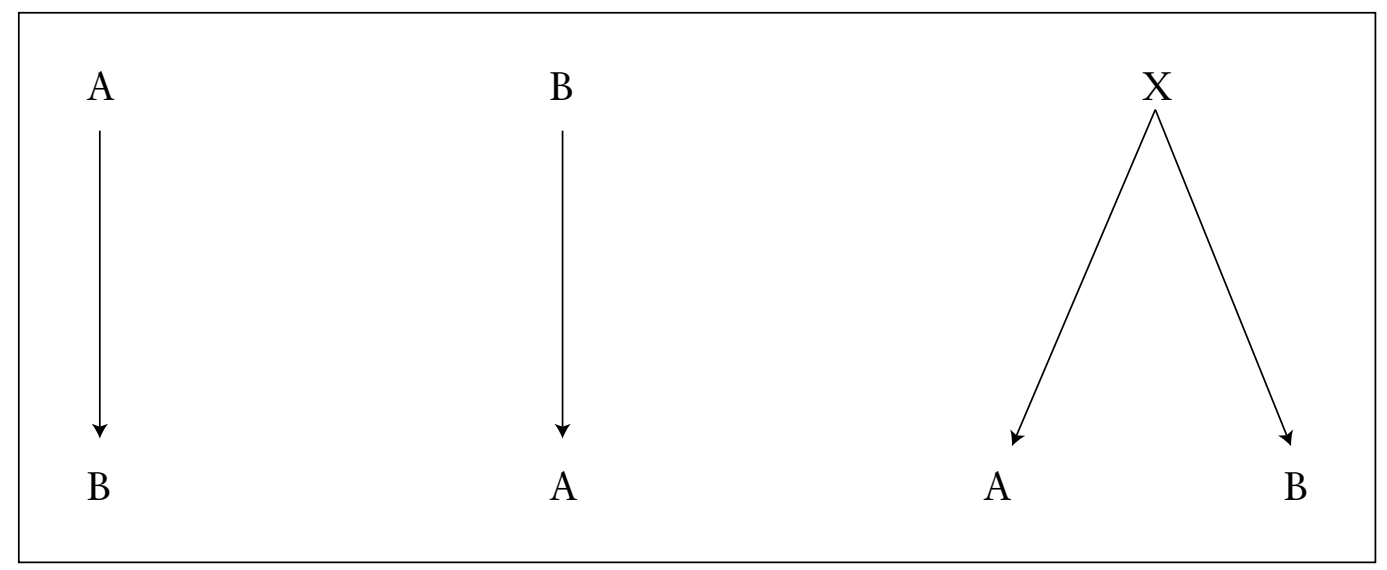

1. irudia. Baztango 1750eko eliza-aginduen harremana.

Ez da erraza jakiten bata bestearen kopia den ala biak hirugarren eredu batean oinarritu ziren; Ondarrak (1982, 388. or.) dioenez, biak dira beste itzulpen baten kopiak, baina ez dakigu zertan oinarritzen den baieztapen hori egiteko. Edonola ere, bi bertsioen arteko desberdintasunak zein diren kontuan hartuta, iduri luke biek kopiatu dutela hirugarren testu batetik. Hala ere, edizioaren oharretan ikus daitekeenez, kopiatzaileek (edo agian kopiatzaileetako batek bakarrik) bere hautuak egin bide dituzte grafia aldetik bederen, hor baitago bi aldaeren arteko desberdintasun nagusia.

Bestalde, itzulpenaren egileak, edo kopiatzaileak bederen, nor izan ziren jakiten ere ez da erraza. Herriko abade, erretore eta bikarioei zuzenduta dago gotzainaren agindua herritarren artean zabaltzeko ardura; beraz, itzultzailea ere horietakoren bat izan zitekeela pentsa daiteke. Orduko bataio-liburuak begiratu ondoren, jakin dezakegu 1750ean Elbeteko apaiza Felipe Gaston de Iriarte zela, hain zuzen ere, euskarazko aginduaren azpian, beste letra eta tinta batez, izen-abizen horiek datoz, baina bataio-liburuko eta aginduko letra mota erkatuz gero, bistakoa da esku desberdinek idatzitakoa dela: $<\mathrm{A}>,<\mathrm{M}>,<\mathrm{G}>$ eta $<$ E $>$ letra larriek ez dituzte trazu berberak, ezta $<$ g $>,<$ e $>,<\mathrm{l}>$, $<\mathrm{t}>$ beste zenbait letra xehek ere. Elizondokoan ere egoera berbera bide da. Kasu honetan, gaztelaniazko azalpena idatzi zuena Elizondoko bikario zen Manuel de Saraspek ${ }^{2}$

1 Elbetekoak ez baina Elizondokoak gaztelaniazko aginduaren kopia bat ere badakar, eta akabuan halaxe jartzen du: «El mismo edicto traducido del castellano a nuestra lengua vulgar, para que su sentido genuino se pueda explicar con mayor claridad y facilidad a los fieles».

2 Ez da transkripzio ziurra. Hainbat aldiz agertzen da bikarioaren sinadura, baina hasieran Saras- ondo irakurtzen den arren, ondoren errubrika dauka sinadurak eta ez da abizenaren bukaera ikusten; halere, -pe bukaera dela dirudi. Sarassape ere izan liteke, baina ez da abizen ezaguna. 
idatzi zuela ematen du; bereak dira Elizondoko 1750ko bataio liburuko sarrerak eta letragatik irudi du berak idatzi zuela gaztelaniazko zatia, baina euskarazkoa beste esku bat da, letrek trazu ezberdina dute, zalantzarik gabe.

\section{FONTES CRITICAE PIXKA BAT}

Dakigula, 1750eko aginduaren euskarazko ordaina, lehen aldiz, Apat Echebarnek (1971, 67-73. or.) eman zuen ezagutzera, baina orduko hartan Elbetekoa bakarrik argitaratu zuen, zatika eta grafia eguneratuarekin. Hamarkada bat geroago, Ondarrak (1982) osorik eman zuen Elbetekoa, eta oharretan Elizondokoaren aldaerak markatu zituen.

Orriokoa izan zen azkena ezagutzen. Satrustegik (1984, 1987, 80-81. or.) eman zuen testua ezagutzera, itxuraz, Orrion bertako parrokian J. M. Pastorrek aurkitu ondoren. Dirudienez, Satrustegik eskuizkribuaren fotokopia erabili zuen bere edizioa paratzeko. Egun ez dakigu testua non dagoen. Orrioko elizaren ardura dutenekin hitz egin nuen, baina ez dute honen berririk eta Iruñeko Elizbarrutiko Artxiboko katalogoan ez dut arrastorik aurkitu.

Baztangoei dagokienez, Elizondon eta Elbeten idatzitako lekukotasunak izan arren, gaur egun bi eskuizkribuak Iruñeko Elizbarrutiko artxiboan daude jasota. Elbetekoa 1676an idazten hasi ziren Cuentas de Elvetea / Ytem $=$ de dif.tos al fin parrokia liburuan dago josirik, 67. orrialdetik aurrera. Elizondokoa, aldiz, Cuentas. Mandatos. Inventario. Año de 1564 izenburua daraman dokumentuan dago, 144v foliotik aurrera. Esan beharrik ez, edizio honetarako jatorrizko bi eskuizkribuak erabili dira, Iruñean biak ikusteko aukera izanda.

Testuak lehenagotik ezagun eta argitaratuak baziren ere, interesgarri ikusi da Baztan eta Elbeteko lekukotasunok berriro editatzea eta erkatzea, Ondarrak zituen huts batzuk zuzendu (adibidez, Ondarrak bere edizioan causatzen $<67 \mathrm{r}>$ dakar, baina Ak causacen dauka eta Bk causatcen) eta jaso ez zituen aldaketa batzuk agertzeko (adibidez, Ondarrak ez zituen jaso A erreprendituco : B erreprehendituco moduko alternantzia horiek). Horretaz gain, testuaren azterketa dialektologikoa egiteak orduko, XVIII. mendearen erdialdeko, Baztango edo Nafarroako mintzoak hobeto ezagutzen lagun dezake.

\section{EDIZIOAZ BI OHAR}

Esan denez, edizio hau egiteko ezagutzen ditugun bi bertsioen jatorrizko eskuizkribuak erabili dira. Hain zuzen ere, biak daude Iruñeko Elizbarrutiko Artxiboan eta bertan zuzenean ikus daitezke.

Edizioaren oinarritzat bat aukeratu behar eta Elbetekoa (A) hartu da, baina aparatu kritikoan Elizondoko (B) testuak dituen aldaerak jaso dira. Dena den, hutsen kasuan, Elbetekoa zuzendu da, Elizondokoa eta Elbetekoaren usus scribendi-a kontuan hartuta. Halakoen berri kasuan kasuko aparatu kritikoan ematen da. Noski, orrialdeen zenbakiak Elbetekoari dagozkio. 
Transkripzioa dela eta, hemen aurkezten den honek edizio filologikoa izan nahi du. Horretarako, A testuak duen jatorrizko grafia mantendu dut oro har, baina hitzen banaketa eguneratu. Halaber, testuan aurkitutako hutsak oro zuzendu eta oharretan eman dut horien berri.

\section{TESTUA}

$<67$ r $>$ Don Gaspar de Miranda eta Argaiz Iaungoicoaren ${ }^{3}$ eta sede apostolicoaren graciaz, Yruñeco obispoa, erregueren consejucoa etc.

Gure obispado huntaco presuna fiel gucieri aditcera ematen dabegu, daudelarican handizqui eta seriosqui erreprenditu ${ }^{4}$ eta meachatuac danza publicoac Aita Sainduaz ${ }^{5}$ eta Escritura Sainduaz, bai eta ere ${ }^{6}$ daudelarican ${ }^{7}$ debecatuac, hala erreinu huntan, nola bercetan $^{8}$ escomicu eta censura bortitcen penan, canon sagradoez, concilioez eta hanitz arzobispo eta obispo saindu eta iaquinsunez. Halaber, debecatuac daudelarican haniz ${ }^{9}$ principe, erregue eta monarca handi eta piadosoez, hoquen conseju eta tribunale errealez pena handien azpian, eta leheneco mendetaco ${ }^{10}$ danzac, cein eguiten baicituzten ${ }^{11}$ guizonquiec guizonquiequin eta emaztequiec ${ }^{12}$ emaztequiequin, daudelarican continuoqui meachatuac ${ }^{13}$ eta erreprobatuac misionista apostolico zeloso zuhur eta piadosoenez ${ }^{14}$. Nolaz eztira erreprendituco ${ }^{15}$, meachatuco ${ }^{16}$, erreprobatuco eta halez becembatean ${ }^{17}$ debecatuco ${ }^{18}$ eta casatuco oraico demboretaco danzac, ceinetan iuntatcen baitira guizonquiac emaztequiequin, presuna gazteen desenfrenatu edo frenoric gaveco ${ }^{19}$ visitaren medioz, elcarrequin duten tratu eta comunicazionearen medioz, causacen ${ }^{20}$ duten

3 Iaungoicoaren] A Iaungoicoaren: B Jaungoicoaren.

4 erreprenditu] A erreprenditu : B erreprehendituac. An jarraian zerbait tatxaturik, ziurrenik <ac>.

5 Sainduaz] A sainduaz: B sainduez. An <i> lerro artean gehitua.

6 bai eta ere] A bai eta-ere : B bai-eta-ere.

7 daudelarican] A deudelarican: B daudelarican.

8 bercetan] A bercetan: B bertcetan.

9 haniz] A haniz: B hanitz.

10 mendetaco] A-n zuloa dago -ac- espero dugun lekuan.

11 baicituzten] A baicituzten : B baitcituzten.

12 emaztequiec] A emaztequiac: B emaztequiec. Ak dituen gainerako pluraleko ergatiboak ikusita, hemengoak hutsa dirudi.

13 meachatuac] A meachatuac: B mehachatuac.

14 piadosoenez] A piadoso-onez: B piadoso-enez.

15 erreprendituco] A erreprendituco : B erreprehendituco.

16 meachatuco] A meachatuco: B mehachatuco.

17 halez becembatean] A halez becembatean : B ahalez bezambatean.

18 debecatuco] A debatuco : B debecatuco.

19 gaveco] A gaveco: B gabeco.

20 causacen] A causacen : B causatcen. 
escandalo publicoaren medioz, ezarcen ${ }^{21}$ baldin badituzte arimac galceco peligro claro eta aguerian? Nolaz eztira erreprendituco ${ }^{22}$ oraico $^{23}$ danzac, eguiten diralaric ${ }^{24}$ haalica$\mathrm{CO}^{25}$ soiñuric alegre eta vicienequin, carrera, lasterca eta errecontrada deshonestequin? Eguiten $^{26}$ diralaric ${ }^{27}$ lujuriaren ${ }^{28}$ edo loiqueriaren ${ }^{29}$ pozoin infernal eta hilgarri ${ }^{30}$ hartara probocatcen dituzten accione, iguitce, movimendu eta uquitce desonestequin? Danzatic gueldicen ${ }^{31}$ diralaric $^{32}$ errefrescatcera, edatera? Dancetan eguiten dituztelaric arcoac, zubiac, ceinen azpitic danzan pasatcen baita Demonioa? Danza hoc eguiten diralaric $^{33}$ ez solamente lecu publicoetan bainan bai eta ere $^{34}$ estalpetan, portaletan, ezcaratcetan berariaz eta mottibo ${ }^{35}$ gutirequin $\left\langle 67 \mathrm{v}>\right.$ bilatcen dituzten arteca mearretan ${ }^{36}$ Profanatcen eta menospreciatcen dituztelaric hanicetan ${ }^{37}$ templu sainduac, basilicac, ermitac, eliza atheac ${ }^{38}$, cimiterioac? Davilzalaric egunaz eta gauaz ${ }^{39}$ plaza publicoetan, videtan eta campo libretan ${ }^{40}$ Danza hotarat iuntacen ${ }^{41}$ direlaric ez guttitan ${ }^{42}$, eta bai gure dolore handi batequin eliza guizonac ${ }^{43}$, bai eta $\mathrm{ere}^{44}$ ordena sainduac pretenditcen dituztenac, ordenatceco pretensionea duten dembora ${ }^{45}$ berean, ceintaz baitira hanitz exemplare. Eta hare gueiago ${ }^{46}$, badirela hotaric cembait danzaco maestru direnac, hala guizonquieri ${ }^{47}$, nola emaztequieri danzan eracustea oficiozat hartua daducatenac?

21 ezarcen] A ezarcen: B ezartcen.

22 erreprendituco] A erreprendituco : B erreprehendituco.

23 oraico] A oraico : B orayco.

24 diralaric] A diralaric: B direlaric.

25 haalicaco] A haalicaco: B ahalicaco.

26 Eguiten] An - $n$ lerro artean.

27 diralaric] A diralaric : B direlaric.

28 lujuriaren] A lujuriaren: B luxuriaren.

29 loiqueriaren] A loiqueriaren: B lohiqueriaren.

30 hilgarri] A hilgarri: B hil-garri.

31 gueldicen] A gueldicen: B guelditcen.

32 diralaric] A diralaric: B direlaric.

33 diralaric] A diralaric: B direlaric.

34 bai eta ere] A baieta ere : B bai-eta-ere.

35 mottibo] A mottibo: B motivo.

36 mearretan] A mearretan: B meharretan.

37 hanicetan] A hanicetan: B hanitcetan.

38 eliza atheac] A eliza atheac: B eliza-atheac.

39 gauaz] A gauaz: B gahuaz.

40 campo libretan] A campo-libretan: B campo libretan.

41 iuntacen] A iuntacen: B iuntatcen.

42 guttitan] A guttitan: B gutitan.

43 eliza guizonac] A eliza-guizonac: B eliza-guizonac.

44 bai eta ere] A bai-eta ere : B bai-eta-ere.

45 dembora] An hitzaren bukaeran $<\mathrm{n}>$ dago tatxaturik.

46 gueiago] A gueiago: B guehiago.

47 guizonquieri] An orriak zuloa du hitz honetan, $<\mathrm{n}>$ eta $<\mathrm{q}>$ ren artean hain zuzen ere; atzeman litezkeenez, zuloak hiru hizkiri eragiten die. 
Heritua dagoelaric, bada, eta cutsatua izurri ${ }^{48}$ eta eritasun ${ }^{49}$ mortal huntaz gure obispadotasuneco parteric gueiena ${ }^{50}$, eta deseacen ${ }^{51}$ dugularic $^{52}$ erremedioa $^{53}$ ematea ecin erranezco gaitceria espiritual eta ${ }^{54}$ temporal huni, eta nahi derabeztegularic ${ }^{55}$ descubritu eta aguertu fiel gucieri Satanasen invencione, engañu eta trampa gorde, estali, secretu, eta segurac, bay eta ${ }^{56}$ luxuriaren, deshonestidadearen gaitz eta calte dudaric gabecoac. Halaber, nahi ditugularic guiristino ${ }^{57}$ fiel guciac athera eta libratu ignorancia eta zoratasun huntaric, ceinetan vici baitira leguearen eta arrazoinaren contra, entregatuac eta emanac diversione gaixto huni, Satanasen engañu huni cein baita yturburua ${ }^{58}$, herroa eta zaiña ${ }^{59}$, ceinetaric sorcen ${ }^{60}$ baitira puebloetan, errietan erreinacen ${ }^{61}$ eta gueienic ${ }^{62}$ aurquicen diran ${ }^{63}$ vicioac. Bada, arrazoin hunengatic Nafarroco ${ }^{64}$ legueac deitcen du, hicendazen du danza "oficina, ceinetan trabajatcen, moldatcen, apaintcen eta eguiten baitira Jaungoicoaren ${ }^{65}$ ofensac eta errietaco escandaloac».

Gure issilic egoite cortes hau hizan ez dadien, bada, causa ${ }^{66}$ eta motiboa ${ }^{67}$ fielen seculacotz galceco, eta Jaungoicoaren, munduaren, eta guizonen aitcinean hizan ez gaitecin omisione edo lazaqueria huntaz ${ }^{68}$ ahalquetuac, ceren consentitcen eta permiti$\operatorname{cen}^{69}<68 \mathrm{r}>$ ditugun dancetaco ${ }^{70}$ abusione gaisto hoc, eta ${ }^{71}$ placer gueiago ${ }^{72}$ dugularic icusteaz gure subdito eta menecoac danzatic campoan, penitenciarequin tristatuac eta melancolia justo batean sartuac, ecen ez dancetaco bozcario eta diversione gaistoan,

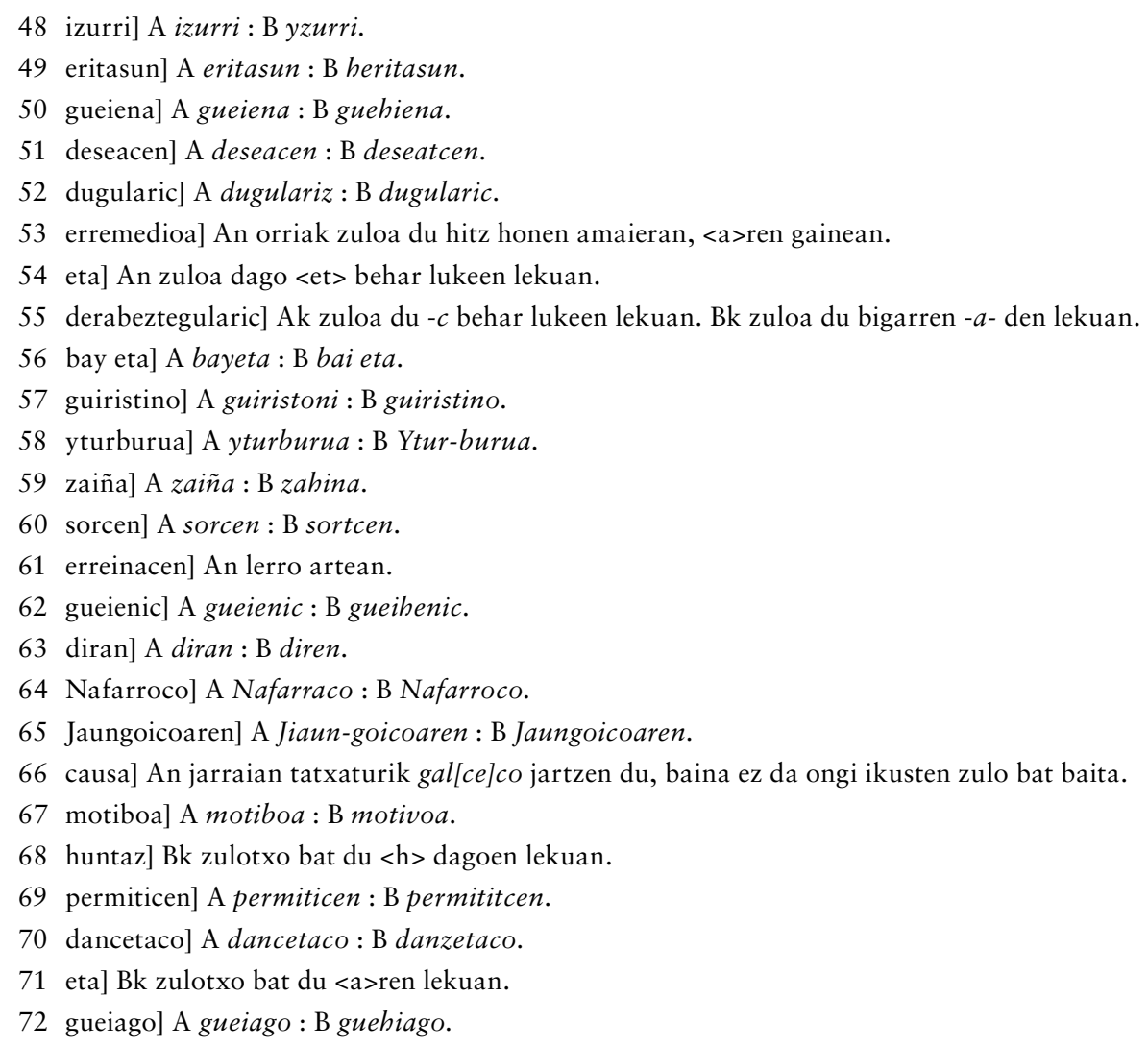


Satanasen ${ }^{73}$ sare eta lazo segur huntan nahasiac eta diversione torpe hunen lecuan nahi dugularic ezarri sacramenduen maiz errezebicico ${ }^{74}$ leguea, constumbreen garbitasuna eta guizonquieri guizonquien, emaztequieri emaztequien, bat bederari bere estaduaren arabera divertitceco modu inocente eta garbia, experienciac eracusi ${ }^{75}$ daucularic eztirela asqui fruitu guttitacoac ${ }^{76}$, hizan direla lehen hartu ciren providenciac eta limitacioneac edo naurriac ${ }^{77}$, ceinequin danzac casatu gabe nahi baitciren quendu dancetaco abusione eta desordenamenduac. Bada, presunen groseriac eta adimenduen escolatu faltac ez dituzte ezagutu nahi noraño ${ }^{78}$ allegacen diren diversione honestaren legueac. Harengatic, bada, dancetaco desordenamenduec, abusionec, fielen excesoec eta principalqui gure concienciac lehiaturic aurquicen ${ }^{79}$ gara obligatuac eta borchatuac exceso ${ }^{80}$, abusione eta desordenamendu hoquen desterracera ${ }^{81}$; hala nola desterracen ${ }^{82}$ baititugu presenteco edicto edo ordena hunen medioz, ceinetan hanitz hala elicetaco ${ }^{83}$ nola erreinuetaco principen arabera, concilio eta Aita Sanduen ${ }^{84}$ arabera usa ${ }^{85}$ eta valia guindeiztequelaric azqueneco bortiztasun eta castiguaz, usatcen ${ }^{86}$ eta valiatcen baicara ${ }^{87}$ piedadeaz, benignidadeaz, consideraturic piedadea izanen ${ }^{88}$ dela motiboric hoberena eta poderosoena, fielec consenti dezaten ${ }^{89}$ guc hain justoqui ${ }^{90}$ deseacen ${ }^{91}$ duguna. Manatcen dugu Elizaco $^{92}$ precepto edo manamenduaren azpian eta, halaber, excomicuric handienaren penan latae sentenciae $\langle 68 \mathrm{v}\rangle$, erran nahi baitu, bereala ${ }^{93}$ danic excomicaturic guelditceco penaren azpian; bay eta ere ${ }^{94}$ berroguei ${ }^{95}$ eta amar $^{96}$ duhaten multaren penan, cein

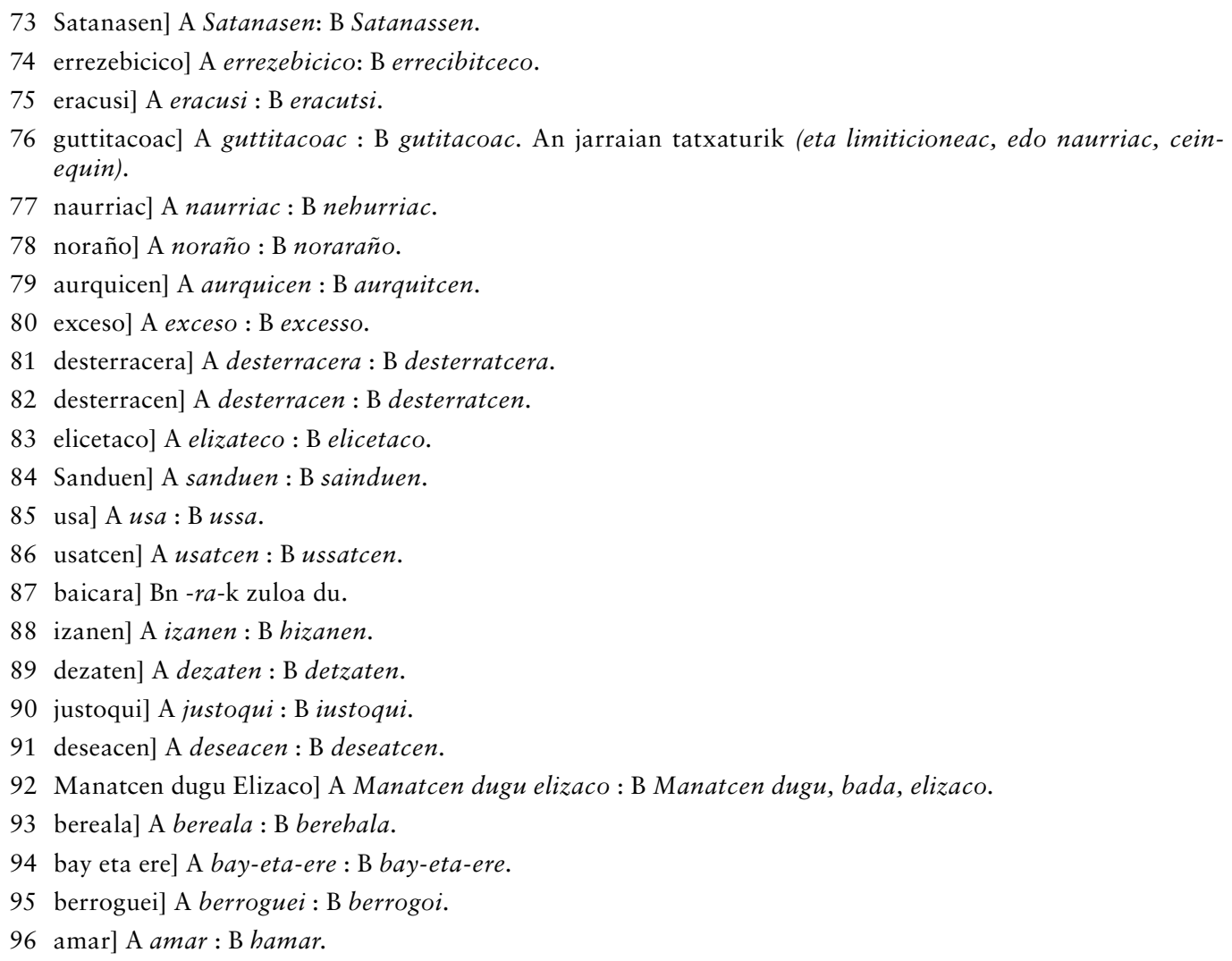


aplicatuco baitira aitormendu apostolicoaren arabera. Eta hare gueiago ${ }^{97}$, avisu ${ }^{98}$ ematen dugularic edicto edo manamendu huntan ordenatcen ditugun gauzac guardatcen ez dituztenen ${ }^{99}$ contra usatuco ${ }^{100}$ ditugula gure potestadeac ussa ahal detzaquen castigu guciac. Diogu verriz ere, erran diren penen azpian, manacen ${ }^{101}$ ditugula ${ }^{102}$ edocein presuna suerte, edocein estadu, condicione eta calidadetacoac hizan daitecin, eztezatela eguin guizonquiac emaztequiequin iuntacen diran ${ }^{103}$ danza publicoric, mezac eta oficio divinoac eguiten diren demboretan, ez eta gahuaz ere eta nioiz ${ }^{104}$ ere, ez eliza athetan, cimitorietan, lecu sainduetan, basiliquetan, hermitetan eta hoquen inguruetan, ez eta ere $^{105}$ videetan $^{106}$, campañetan, palazaz ${ }^{107}$ campoan, estalpetan, portaletan, ezcaratce$\tan , \operatorname{artteca}^{108}$ mearretan $^{109}$ eta lecu secretu eta erretiratuetan. Eta ceren providencia cuidadoso hunec ez baitu erdiesten, dancec causacen ${ }^{110}$ dituzten desordenamendu, exceso $^{111}$ eta caltetaric ${ }^{112}$ partte ${ }^{113}$ ttipi batten ${ }^{114}$ casatcea baicen gure deseioa lizatequelaric dancen osoqui desterratcea ${ }^{115}$, ussacen ${ }^{116}$ dugularic eztitasunaz, benignidadeaz gañeraco fiel guciequin, fidacen ${ }^{117}$ garelaric hequin ussacen ${ }^{118}$ dugun medio suave eta ezti onequin ${ }^{119}$. Eta hunen medioz fielec beren aita eta arzainaren aditceco eta obedecitceco duten docilidade edo mansotasunaren medioz erdiesico ${ }^{120}$ dugula deseatcen dugun efectua. Erran diran pena eta censuren azpian, manatcen ditugu eliza guizonac

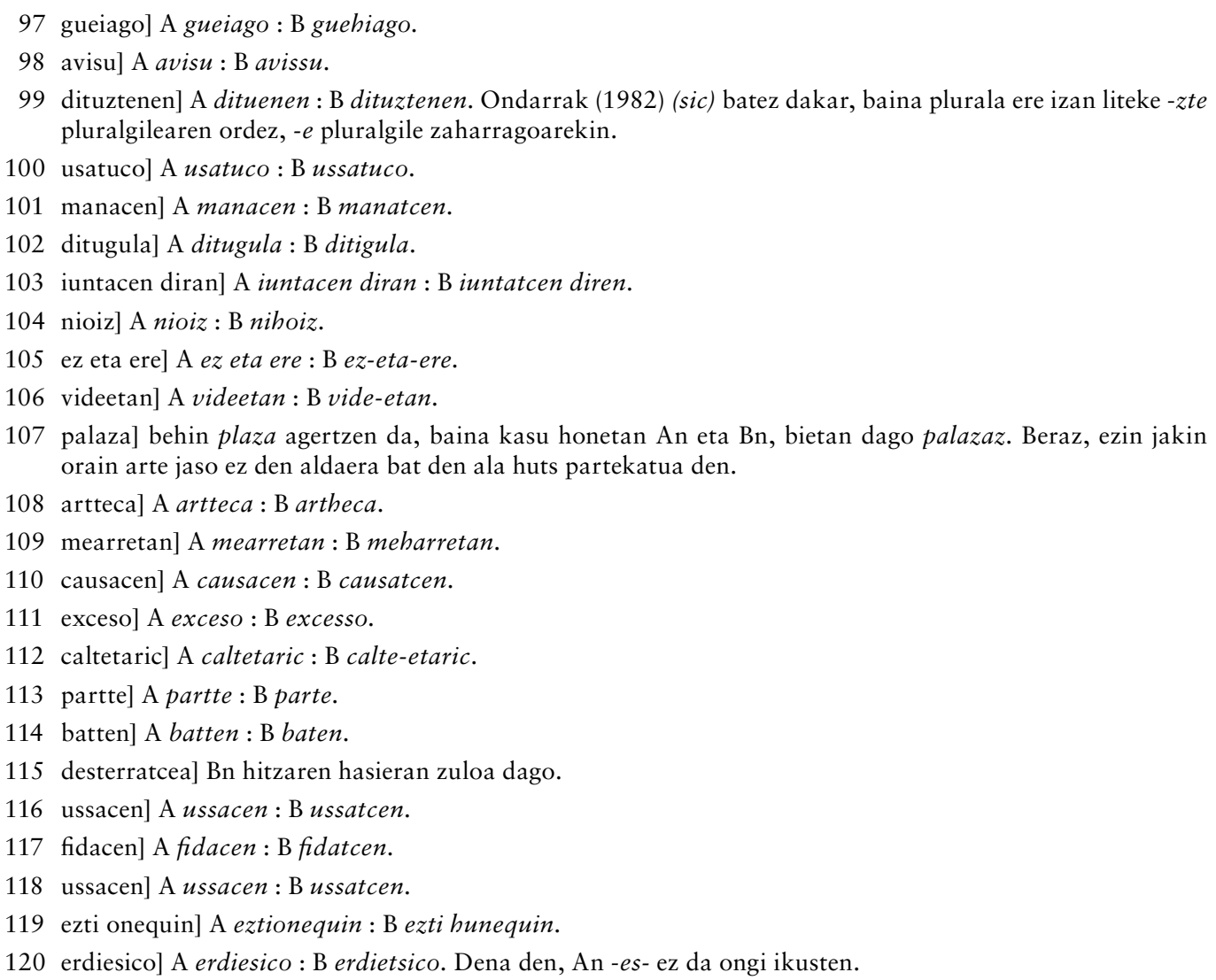


ez publicoan eta ez secretoan ${ }^{121}$, ez daitecila iunta danza hotara, eta ez daitecila danza edocein $^{122}$ pretestu izan ${ }^{123}$ arren. Eta ordena sainduac pretenditcen dituztenac hizanen dira iaquinac eztirala ${ }^{124}$ recibituac $^{125}<69 \mathrm{r}>$ hizanen ordenetara faltaric eguiten badutte pontu hunetan.

Eta erran diran ${ }^{126}$ gauzac hobequiago compli daitecingatic exorta ${ }^{127}$ ditugu amolsuqui eliza guizon guciac, ocasione duten guziez ${ }^{128}$, exorta detzaten fielac utz dezaten ${ }^{129}$ dancetaco diversione gaixtoac. Seguratcen ditugularic dolore andia causatuco daucutela ez balin badituzte eguiten exortacione edo avisu hoc. Bay eta castiguric handienarequin hizanen direla punituac hizaten badira causa, ematen badute ocasione eta mottibo ${ }^{130}$ dancen sostengatceo eta conservatceco. Bañan are especialquiago exortatcen ditugu eta necesario bada manatcen ditugu Elizaco buruzagui, erretor, abade, vicario eta hoquen thenienteac beren ${ }^{131}$ predicu, platica ${ }^{132}$, confesonario eta conversacionetan, eguiten dutenean $^{133}$ solasa $^{134}$ errietaco guizonic consideratuenequin, puebloarequicotz auttorida$\mathrm{de}^{135}$ cembait dutenequin, otoiz ${ }^{136}$ eta $^{137}$ encarga dezaten ${ }^{138}$ dancen gueldiarazteaz ${ }^{139}$ eta osoqui ${ }^{140}$ desterra arazteaz ${ }^{141}$, ecen $\mathrm{ez}^{142}$ horaicoaz $^{143}$ denaz bezembatean ${ }^{144}$. Ezta gure intencionea fielen trista araztea ${ }^{145}$, Aita Sainduec, canon sagradoec ${ }^{146}$ eta concilioec

121 secretoan] A secretoan: B secretuan.

122 edocein] A edocein : B edo cein.

123 izan] A izan : B hizan.

124 eztirala] A eztirala: B ez tirela.

125 recibituac] A recibituac: B errecibituac.

126 diran] A diran: B diren.

127 exorta] A exorta : B exortatcen.

128 guziez] A guziez: B guciez.

129 dezaten] A dezaten: B detzaten. A testuak afrikatuak bereizten ez dituenez, anbiguoa izan daiteke adizkia, baina testuinguruak eta B testuak erakusten dute plurala dela eta, beraz, afrikatu irakurri behar dela.

130 ocasione eta mottibo] A ocasione eta mottibo : B ocassione eta motivo.

131 beren] An zuloa du paperak hitzaren amaieran.

132 platica] An bi zulo ditu hitzak, biak dauden bi <a> gainean.

133 dutenean] An jarraian tatxaturik dator: (othoi[z] [...]aga dezaten.

134 solasa] A solasa : B solassa.

135 auttoridade] A auttoridade: $\mathrm{B}$ authoridade.

136 otoiz] A otoiz : B othoitz.

137 eta] An <a> dagoen lekuan zuloa dago.

138 dezaten] A dezate: $\mathrm{B}$ detzaten.

139 gueldiarazteaz] A gueldi-arazteaz: B gueldi-arazteaz.

140 osoqui] A osoqui : B ossoqui. An zuloa du lehenengo <o>k.

141 desterra arazteaz] A desterra-arazteaz: B desterra-arazteaz. An lehen bi $<\mathrm{e}>\mathrm{k}$ zulo bana dute paperean.

142 ecen ez] A ecen-ez: B ecen-ez.

143 horaicoaz] A horaicoaz: B horaycoaz.

144 bezembatean] A bezembatean: B bezambatean.

145 trista araztea] A trista araztea: B trista-araztea.

146 sagradoec] An $<\mathrm{d}>$ ez da ongi ikusten. 
danza eta zarabanden contra eguiten dituzten exclamacione eta ohiju ${ }^{147}$ borticequin ${ }^{148}$, expresione mimberequin eta ponderacione viciequin. Halaber, Jesu Christoren entrañen amoreagatic exortatcen eta encargatcen ditugu gure obispado huntan diren ciudadetaco eta errietaco justiciac lehen bai lehen ${ }^{149}$, arimen celo eta piedade handi batequin aplica daitecin erran diren exceso ${ }^{150}$ eta desordenamenduen, ceinec bere ${ }^{151}$ lecuetaric desterratcera eta casatcera. Huntaracotz valiacen $\left.{ }^{152}<69 \mathrm{v}\right\rangle$ direlaric industriaz, moduz eta mañaz, pensatcen eta bilatcen dituztelaric diversione inocente, modest eta honestac, ceinetan presuna gazteec ${ }^{153}$, nor bere calidadearen arabera, emplega baitezaquete bestetan, beren debocioneac ${ }^{154}$ eguin eta ondoan sobracen zaien ${ }^{155}$ dembora.

Manatcen dugu, alaber, erran diren pena eta censuren azpian, elicetan, letanietan, procesionetan, cofradia ta ${ }^{156}$ berce Elizaco funcionetan ez dadien usa ${ }^{157}$ tamborinic ez eta ere $^{158}$ danzatceco cervizatcen ${ }^{159}$ diren instrumentu profanoric, ceren baitire ${ }^{160}$ Elizaco disciplina sainduaren contraco gauzac. Eta hala diren bezala canon sagradoez daude debecatuac elizetan eta elizetaco choruetan. Eguia da Bestaberriz eta Eguberriz consenticen ${ }^{161}$ dituela Elizac guisa huntaco ynstrumentuac, eta soilqui guizonquien danzac, fielen ussanza comun eta generalac eracusten duen bezala. Halaber berean, erran diren pena eta censuren azpian, manatcen ditugu elizetaco buruzaguiac, erretorac, abadeac, vicario eta hoquen thenienteac ${ }^{162}$ presenteco edicto hau publica eta lei detzatela Bazco garizumaco lehembecico egunean, meza nausiaren ${ }^{163}$ errateco demboran, nihorc ere alega ez dezan emen ordenaturic eta manaturic dauden gaucen ignorancia. Eta baldin nior $^{164}$ ausartacen ${ }^{165}$ bada eman ditugun ordena hoc despreciaturic, lehen bezalaco lecuetan, ohi nola danzatcera eta erran diren ynstrumentu profanoac eliza eta coruetan ${ }^{166}$

147 ohiju] A ohiju: B ohiyu.

148 borticequin] A borticequin: B bortitcequin.

149 lehen bai lehen] A lehen-bai-lehen: B lehen-bay-lehen.

150 exceso] A exceso : B excesso.

151 bere] A bere: B beren.

152 valiacen] A valiacen: B valiatcen.

153 gazteec] A gazteac: B gazteec. Ak dituen gainerako pluraleko ergatiboak ikusita, hemengoak hutsa dirudi.

154 debocioneac] A debocioneac: B devocioneac.

155 zaien] A zaien: B zayen.

156 ta] A ta: B eta.

157 usa] A $u s a:$ B ussa.

158 ez eta ere] A ez eta ere : B ez-eta-ere.

159 cervizatcen] A cervizatcen : B cervitzatcen.

160 baitire] A baitire : B baitira.

161 consenticen] A consenticen : B consentitcen.

162 thenienteac] A thenienteac: B thenientehac.

163 nausiaren] A nausiaren: B nabusiaren.

164 nior] A nior : B nihor.

165 ausartacen] A ausartacen: B ausartatcen.

166 coruetan] A coruetan: B choruetan. 
sartcera, hunelacoac publicatuco dira excomunicatuzat ${ }^{167}$ eta apartatuco dira oficio divinoetaric. $\mathrm{Nai}^{168}$ dugu, guisa verean ${ }^{169}$, bat bederac edicto hunen traslado bat ezar dezan elizaco liburuan, visitetaco manuen ondoan, eta publica eta lei detzaten urte ${ }^{170}$ guciez, Bazco garizumaco leembecico ${ }^{171}<70 \mathrm{r}>$ egunean, eta hortaz landa, conveni eta necesario dela iduricen zaien ${ }^{172}$ besta gucietan.

Iruñeco ziudadean ${ }^{173}$ emana marchoaren hamabigarren egunean, mila zazpitan eun eta berrogoy ${ }^{174}$ eta hamarrean.

Gaspar, Yruñeco obispoa, obispo ene jaunac manaturic.

Dr. Dn. Joseph Eladio Colado. Secret.a (Dn. P.O Phelipe Gaston de Iriarte)

\section{HIZKUNTZA-IRUZKINA}

Grafian, orduko testuek dituzten ezaugarriez gain, interesgarri dateke bi testuen arteko konparaketa egitea. Hain zuzen ere, Ak ez dituen zenbait $<\mathrm{h}>$ grafiko ditu B testuak, beraz, erreprenditu : errepehendituac; meachatuac : mehachatuac; loiqueriaren : lohiqueriaren moduko txandaketak ageri dira. Bestalde, dirudienez, Bn afrikatuak markatzen saiatzen bada ere, ez da hain indartsua joera An: gueldicen : B guelditcen, iuntacen : iuntatcen, etab. Txistukari afrikatuez gain, bestelako txandaketa batzuk ere badira bi testuen artean: Ak ohiju (69r) eta Bk obiyu; edonola ere horrek ez du ahoskera zein zen zalantzarik sortzen. Duda gehiago eragiten du gaztelaniazko mailegu den lujuriaren (67r) hitzaren ahoskerak. Ak $<\mathrm{j}>$ darabil, Bk, ordea, $<\mathrm{x}>$ : luxuriaren. Beharbada, bi kopiatzailek desberdin ahoskatzen zuten mailegua. Azkenik, A testuak hitz batzuetan <tt> erabiltzen du, baina ez dago argi zergatik: mottibo (67r), artteca partte, batten (68v), badutte (69r). Horietan, azkenekoa izan ezik, B <t> erabiltzen du. Beste kasu batzuetan, ordea, $<\mathrm{tt}>$ digrafoa herskariaren sabaikaritzea islatzeko erabiltzen dela ematen du: guttitan (67v), guttitacoac (68r), ttipi (68v). Azken kasu horretan Bk ere $<\mathrm{tt}>$ erabiltzen du.

Fonologiaz den bezainbatez, ${ }^{*} j$ - zaharraren ahoskera sabaiaurrekoa dela dirudi: Iaungoicoaren (67r), iaquinsunez (67r), iaquinac (68v); hots hau maileguetan ere egiten da, besteak beste, ondoko adibidean: iuntatcen (67r). Irudiz, Bruno Etxenikek Elizondoko hizkerara itzulitako dotrinan ere halaxe da: yotzen, yauna, yabeaïn, yuzcatu, yuramentu,

167 excomunicatuzat] An lerro artean.

168 Nai] A nai : B nabi.

169 verean] A verean : B berean.

170 urte] A urte: B urthe.

171 leembicico] A leembicico : B lehenbicico.

172 irudicen zaien] A irudicen zaien: B iruditcen zayen.

173 ziudadean] A ziudadean: B Ciudadean.

174 zazpitan eun eta berrogoy] A zazpitan eun eta berrogoy: B zazpietan ehun eta berrogoi. 
yuzcatzera, etab. ditu. Merezi luke ohartaraztea eliza-aginduaren mende bereko Baztango prediku batean (Lekaroz, 2006) $<\mathrm{i}>,<\mathrm{j}>$ eta $<\mathrm{y}>$ erabiltzen direla eta, batez ere, $<j>$ erabiltzen dela, maileguetan, ustez, [x] hotsa irudikatzeko. Eliza-agindu hauetan, ordea, Etxenikeren itzulpenean bezala, maileguetan ere sabaiaurrekoa dugu. Testu zahar askotan ohikoa den bezala, -al bukaera duten maileguetan -ale egiten da: tribunale (67r). Bestalde, lat. " $(67 \mathrm{r})$, accione $(67 \mathrm{r})$, pretensionea $(67 \mathrm{r})$, diversione $(67 \mathrm{v})$. Mende bukaerako predikuetan ere hala egiten da Baztanen: satisfaccionea, correccione, etab. (Lekaroz, 2006). Etxenikeren itzulpenean ere hori da araua; edonola ere, tentacio aldaera erabiltzen du. Bestalde, ratio/onis maileguaren kasuan -oin egiten da: arrazoinaren, arrazoin (67v). "-ani bukaeraren kasuan, -ain egiten da Baztanen espero bezala: arzainaren (68v). Amaitzeko, $-r z$ - egitura multzoa mantentzen da: bercetan $(67 \mathrm{r})$, berce $(69 \mathrm{v})$. Dirudienez, deseioa $(68 \mathrm{v})$ lekukotasunean $e$-o-ren arteko hiatoa saihesten da, baina deseatcen $(68 \mathrm{v})$ ere badugu. Etxenikek deseyu erabiltzen du; hain zuzen ere, OEHn (s. v. deseo) esaten denez, Baztango eta Zaraitzuko katiximetan eta Añibarroren goi-nafarrerazko lanean agertzen da deseiu.

Izen morfologiara pasatuz gero, Nafarroa gehienean espero bezala, ergatibo plurala -ek da: guizonquiec (67r), desordenamenduec, excesoec, fielec (68r), baina An bi salbuespen dauden, agian hutsak emaztequiac (67r) eta gazteac (69v). Bestalde, erakuslee$\tan -n$ aurretik $o>u$ egiten duten kasuak ditugu: huntaco, buntan (67r), buntaz, huni $(67 \mathrm{v})$. Iduriz, orduko Baztango mintzoan ohiko bilakabidea zen (Lekaroz, 2006). Salbuespen bakarra aurkitu dugu: onequin (68v). Bestalde, hoc da lehen graduko erakuslea: danza hoc (67r), gaisto hoc (68r); eta hemendik eratortzen dira gainerako kasuak: hoquen (passim), hotarat, hotaric (67r), etab. Hirugarren gradukoetan -e-dago: hequin (68v). Izenordainei dagokienez, nior (passim) dago. Bestalde, aditzondoak sortzeko -qui erabiltzen da gaztelerazko -mente atzizkiaren ordain: seriosqui (67), continuoqui (67r).

Oro har, instrumentalean $-s$ erabiltzea goi-nafarreraren ezaugarritzat hartu izan bada ere, Baztanen ez da agertzen ezaugarri hori (Zelaieta, 2008, 188. or.), eta testuok ere horren lekuko dira, instrumentalean sistematikoki $-z$ erabiltzen baita, hementxe adibide batzuk: Aita Sainduaz (67r), sainduaz, sagradoez, concilioez, iaquinsunez (67r). Datibo pluralean -eri daukagu: gucieri (67r), emaztequieri, gizonquieri (67r). Ablatibo pluralari dagokionez, -etaric erabiltzen da: ceinetaric $(67 \mathrm{v})$, lecuetaric $(69 \mathrm{r})$. Bestalde, prolatiboan -zat marka dugu: oficiozat (67r). Horrekin batera, helburu zentzua duen - cotz agertzen da: seculacotz (67v), puebloarequicotz, Huntaracotz (69r).

Aditz morfologiara pasatuz gero, aditz-izenetan egoite $(67 \mathrm{v})$ aldaera zaharra dago, baina orrialde berean ematen dauka, - $i$ - gabe. Bestalde, geroaldia egiteko, -en agertzen da: izanen (passim). Mende luze beranduago Bruno Etxenikek itzulitako Elizondoko dotrinan, sistematikoki, -in agertzen da, izain; Mikelestorena lesakarrak ere (c. 1754) -in darabil beti. NOR-NORI-NORK sailean "eradun erabiltzen da beti: ematen dabegu (67r), nabi derabeztegularic descubritu (67v), eracusi daucularic (68r), causatuco daucutela (69r). Etxenikek dieztegun baina diogulä̈ dakartza; nagusiki, -in- erroa erabiltzen du (gaurko egoeraz, ik. Salaburu \& Lakar, 2005, 107. or. eta hurrengoak). Indikatibotik landako perifrasietan aditzoina erabiltzen da: consenti dezaten (68r), ez daitecila iunta (68v), ez daitecila danza (68v), compli daitecingatic (69r), utz dezaten 
(69r). Bestalde, arestiko adibide horietako batzuetan ikusten denez, daitezen $>$ daitezin eta daitezela $>$ daitezila gertatu da; Salaburuk eta Lakarrek (2005, 95. or.) gaitetzi- eta daitzi- dakartzate Baztango gaur egungo mintzoko formatzat.

Sintaxiari dagokionez, moduzkoan perpausak sortzeko -laric eta -larican, biak erabiltzen dira: daudelarican (passim), diralaric (passim). Bestalde, TOGEN egitura erabiltzen da: fielen seculacotz galceco $(67 \mathrm{v})$, arzainaren aditceco $(68 \mathrm{v})$. Amaitzeko, helburuzkoetan [subjubtiboa + -gatik] egitura agertzen da: compli daitecingatic (69r).

Lexikoaz den bezainbatean, goi-nafarreraz usu ageri den escomicu (67r) agertzen da, Nafarroako testuetan ohikoa den eskomekatu-ren oinarri den izena. Halaber, Iparraldeko tradizio idatzian agertzen den saindu (passim) dugu, gaur egun bezala (Salaburu \& Lakar, 2005). Horrekin batera, presuna (67r), presunen (68r) aldaera ere agertzen da. Ekialde zabaleko orai (passim) aldaera ere idoro daiteke testuan. Bestalde, gizonqui eta emaztequi (passim) maiz agertzen dira testuan. Azpimarratzekoa da gaitceria $(67 \mathrm{v})$ hitza, OEHk ez du hitzaren agerraldi hau jasotzen; ematen duen lekukotasun bakarra Manterolak bere kantutegian jaso eta hortik Duvoisinek hartutakoa da (ik. OEH s. v. gaitzeria). Halaber, testuan obispadotasuneco agertzen da; OEHn adibide bakarra ematen da, Lizarraga Elkanokoarena. Beraz, testu honetakoa litzateke lehen agerraldia. Azkenik, interesgarria da Ak eta Bk duten txandaketa bat: Ak naurriac erabiltzen du, Bk, ordea, nehurriac. OEHn (s. v. neurri) naurri goi-nafarrerazko aldaeratzat hartzen da, eta bi lekukotasun ematen dira: Altsasun Kandido Izagirrek bildutakoa eta Satrustegik (1987) argitaratutako 1751ko sermoian agertzen dena; hiztegiak ez du 1750eko agindu honetakoa jasotzen. Nafar hitz Nafarroako euskalkien hiztegien bilatzaile lexikoan «neurri» bilatuz gero, laurri agertzen da Lizarraga Ergoieneko euskaran, negurri Erroibar eta Esteribarren eta neurri Luzaiden; ez da naurri agertzen.

\section{TESTUAREN FIDAGARRITASUN DIALEKTALAZ ZENBAIT OHAR}

Hatsarre filologikoei jarraikiz, testua finkatu eta hizkuntza ezaugarriak atera ondoren, beste pauso bat egin behar du hizkuntzalariak. Dialekto baten historia eta bilakabidea ezagutu nahi den kasuetan, ikerlariak topatu ohi duen eragozpena izaten da testu idatzia ahozko hizkuntzari leial ote zaion. Bestela esanda, galdera da ea testu idatziak zenbateraino islatzen duen ahozko hizkera. Beraz, Baztango bi lekukotasun hauen aurrean, dialektologoari sortzen zaion galdera da: XVIII. mendeko Baztango mintzoaren lekukotasun fidagarriak dira Elbeteko eta Elizondoko testuok?

Ulibarrik (2015, 62. or.), dioenaren bide beretik, testu guztiak dialektaltzat har daitezke -begira, halaber, Pilch (1988)-, baita Baztango agindu hau ere; eztabaida, beraz, testuaren dialektaltasunean dago:

Gure ustez, testu erlatiboki diatopiko hauek (eta «idazki ez hain fidagarriak» oro har) ezin ditugu zuzenean testu ez-dialektaltzat hartu, pentsatzen baitugu idazlea bere mintzoa erabiltzen ari dela, hori bai, egoera komunikatibo zehatz batean. Koxka honetan dago, alegia, ea gai garen testuan diren ezaugarriak nongoak diren zehazten eta 
are lehen begiratuan «bitxiak» diruditen bestelako ezaugarriak zergatik ageri diren azaltzen; eta horretarako lanari ekitea beste biderik ez dago (Ulibarri, 2015, 62. or.).

Ulibarriren proposamenari jarraikiz, idatzizko testuen bidez dialektologia egin nahi bada, kontuan hartu behar da testuen jatorria, helburua eta egoera komunikatiboa zein diren, ez baitira gauza berbera izebak ilobari idatzitako gutuna (begira Reguero, 2017, 309. or. eta hurrengoak), herri baterako idatzitako dotrinatxoa edo erresuma osorako argitaratutako kristau ikasbidea. Hori dela eta, interesgarria izan daiteke testuen fidagarritasun eskala (Reguero, 2017, 17. or. eta hurrengoak) kontuan izanda aztertzea Baztango eliza-agindu honetako mintzoa.

Itzultzailea nor eta nongoa zen ez badakigu ere, dakiguna da helburu administratibo edo lege-emaile batekin sortu zela idatzia; halakoetan, salbuespenak egon badauden arren, ahozko mintzotik aldentzen da testu idatzia ${ }^{175}$. Edonola ere, Baztango Elbete eta Elizondorako idatzitako testuak direnez, ez da zalantzarik bertako euskaraz baliatu zirela itzulpena egiteko. Hala ikus daiteke, adibidez, erakusleetako - $u$ - horietan eta hok eta hek gisako erakusleetan. Egun ere bi ezaugarri horiek agertzen dira Baztanen (Salaburu \& Lakar, 2005, 67. or.). Halaber, ahozko mintzoaren eragina izan daiteke "eradun saileko hiru adizkiek duten forma: ematen dabegu, nabi derabeztegularic descubritu, eracusi daucularic, causatuco daucutela.

Ahozkotasunetik testu idatzi formalerako jauzia ikus dezakegu, beharbada, genitiboan eta geroaldian. XVIII. mendearen erdialdetik aurrera, goi-nafarrerako mintzo askok erakusten duten ezaugarria da genitiboan -aren $>$-ain eta geroaldian -nen $>$-in egitea. Arestian ikusi dugu mendearen bigarren erdiaren hastapenetan Mikelestorena lesakarrak -in erabiltzen duela sistematikoki geroaldian. Aldiz, 1750. urtea baino lehenagokoek, ordea, ez dute ezaugarri hori ${ }^{176}$, eta eliza-aginduaren bertsio hauek ere ez. Nolanahi ere, mendearen akabuan eriain 'eriaren' eta charrenain 'txarrenaren' aurkitu ditu Lekarozek (2006, 76. or.) Baztango predikuan. Horri loturik, interesgarria da 15. oin-oharrean dioena:

Testuaren egileak ildo bereko batain (Pagola 1995a: 251), gueyagoin (354) edota buruain (374) idatzi zituen-tarteka baino ez, bestalde-Bonaparte Ondarean bildutako predikuetan; gainera, genitiboari ez ezik, haren gainean eratutako kasuei dagozkien adibideak ere utzi zizkigun: gorputzaindaco (245), bazcoaiquin (\& Bazcoarequin; 365). 1800 inguruko S. Bartolomeren sermoian eta beranduagoko Goyenecheren lanetan ere bilakaera berberaren arrasto batzuk daude. Goyenecherena da honako adibide hau: egun gucia guelditcen-da lanen-daco, oficinaindaco, tratuaindaco, asuntuaindaco (Pagola 1995a: 407). Nolanahi ere, Echenique izan zen idatzian ia beti -ain (eta ez -aren) hautatu zuen idazle bakarra (Lekaroz, 2006, 76. or.).

175 Antzekoa bide da 1626an Leitzako apaizaren aurkako auzia dela-eta eliza atarian agertutako testuarena. Satrustegik $(1987,46$. or.) ohartarazten duenez, hizkera espezializatua darabil testuak, herri-hizkeratik aldentzen dena (begira Reguero, 2017, 292-295. or.).

176 Lehenagoko salbuespen bakarra Elizalderen 1735ko dotrinako egoin da (Reguero, 2017, 610. or.). 
Geroaldian ere, Bruno Etxenikek Elizondoko euskarara itzulitako dotrinan izain erabiltzen du beti. Edonola ere, Bonaparteren ondareko Elizondoko dotrina anonimoan, genitiboan -aren eta geroaldian -en erabiltzen dira (Pagola et al., d. g.), eta ondare bereko 1845 eko predikuak, Martin Goienetxe Elizondoko bikarioak irakurri zuenak, -aren du.

Alegia, iduriz, XVIII. mendearen bigarren erdialdeko lekukotasun idatzi batzuetan ahozkoan erabiltzen zen eta ziurrenik egileak berak erabiltzen zuen, -in sartu zen; ez, ordea, sistematikoki. Beharbada, ahozkoan bilakaera abian zen eta ez zen erabat gauzatu, baina, Elizalderen kasuan bezala testuetan itzuri diren lagintxoek edo Mikelestorenak erakusten duen sistematikotasunak pentsatzera eraman gaitzakete forma osoa agertzea zuzentasunaren kontzientzia linguistikoagatik izan daitekeela, hau da, idazleak jakinik -in kalekoa edo sistematikoa ez den ezaugarria dela eta forma osoa -aren dela, bigarrenaren aldeko hautua egin bide zuen, nahiz eta bestea ere, -in, inoiz edo behin erabili idatzian, Elizaldek bezala. Beharbada, hori izan liteke eliza-agindu hauetan -in ez agertzeko arrazoia. Mende bete geroagoko autoreek, batez ere, Bonaparteren itzalpean aritu zirenek, -in-en alde egin zuten idazteko orduan, beharbada dialektoaren ezaugarria islatu nahi zutelako, beharbada ordurako ezaugarria sistematikoa zelako. Beraz, Baztango 1750. urteko mintzoa islatzen duen testu formal baten aurrean bide gaude.

\section{ERREFERENTZIAK}

Apat Echebarne, Á. (1971). Noticias y viejos textos de la «lingua navarrorum». Donostia: Sociedad Guipuzcoana de Ediciones y Publicaciones.

Bidador, J. (2004). Materiales para una historia de la literatura vasca en Navarra. Iruñea: Pamiela.

Lekaroz, G. (2006). Antzinako baztanera: XVIII. mendeko prediku argitaragabe bat. FLV , 101, 69-94.

Mikelestorena, J. (1754). Cerura nai duenac ar dezaquen vide erraza. Iruñea: Martin Joseph Radaren etxean.

OEH = Mitxelena, K. et al. (1987-2015). Orotariko euskal hiztegia . Bilbo: Euskaltzaindia. 5. argit. elektr. 2017: http://www.euskaltzaindia.eus/oeh helbidetik berreskuratua.

Ondarra, F. (1982). Textos en vascuence navarro de Baztán, Nuin y Urdazubi. FLV, 40, 387-402.

Pagola, R. M. et al. (d. g.). Bonaparte ondareko eskuizkribuak - Fondo Bonaparte. Bilbo: Tesitek, Deustuko Unibertsitatea-Bizkaiko Foru Aldundia. http:// bonaparte.deusto.es/bonaparte helbidetik berreskuratua.

Pilch, H. (1988). Dialectology in historical grammar. In Fisiak (arg.), Historical dialectology. Regional and social (417-442 or.). Berlin, New York \& Amsterdam Mouton de Gruyter.

Reguero, U. (2017). Goi-nafarrera arkaiko eta zaharra: azterketa eta testuak (doktorego-tesia). UPV/EHU, Vitoria-Gasteiz. 
Salaburu, P. \& M. Lakar (2005). Baztango mintzoa: gramatika eta hiztegia. Bilbo: Euskaltzaindia \& Nafarroako Gobernua.

Satrustegi, J. M. (1984). El edicto eclesiástico de 1750 en versión vasca de la Cuenca de Pamplona, ASJU, 18(1), 39-52.

Satrustegi, J. M. (1987). Euskal testu zaharrak I. Iruñea: Euskaltzaindia.

Ulibarri, K. (2015). Dotrinazko Sermoitegia: galduriko hizkerak eta dialektologia historikoa (doktorego-tesia). UPV/EHU, Vitoria-Gasteiz.

Zelaieta, E. (2008). Baztan-Bidasoako hizkeren azterketa dialektologikoa. Bilbo \& Iruñea: Nafarroako Gobernua \& Euskaltzaindia. 